\title{
A New TaqMan Real-Time Polymerase Chain Reaction Assay for Quantification of Fusarium virguliforme in Soil
}

G. C. Y. Mbofung, Department of Plant Pathology and Microbiology, A. Fessehaie, Seed Science Center, M. K. Bhattacharyya, Department of Agronomy, and L. F. S. Leandro, Department of Plant Pathology and Microbiology, Iowa State University, Ames 50011

\begin{abstract}
Mbofung, G. C. Y., Fessehaie, A., Bhattacharyya, M. K., and Leandro, L. F. S. 2011. A new TaqMan real-time polymerase chain reaction assay for quantification of Fusarium virguliforme in soil. Plant Dis. 95:1420-1426.

The quantification of the soilborne pathogen Fusarium virguliforme inoculum in soil is important for epidemiological studies of soybean sudden death syndrome (SDS). Classical dilution plating methods to determine inoculum density in soil have yielded inconsistent results due to slow growth, variable colony morphology of the pathogen, and the presence of other fungi with similar phenotype. A TaqMan realtime polymerase chain reaction assay was developed based on sequences of the FvToxl gene of $F$. virguliforme. The gene differed by four single-nucleotide proteins from the other SDS-causing species. Assay specificity was tested on 48 fungal isolates that varied in taxonomic relatedness. Assay sensitivity was appraised on 10-fold serial

dilutions of genomic DNA, conidia suspensions, and soil spiked with conidia. Applicability of the assay was evaluated on field and greenhouse soil samples, and on roots of symptomatic plants. The assay detected only DNA sequences specific to $F$. virguliforme. The detection limit of the assay was $5 \mathrm{pg} / \mu \mathrm{l}, 1,000 \mathrm{conidia} / \mathrm{ml}$, and 1,000 conidia/g soil for genomic DNA, conidial suspensions, and soil with conidia, respectively. The assay was specific to $F$. virguliforme and was used successfully to quantify inoculum density in soil and soybean roots. The assay can be used as a diagnostic tool for rapid screens of field and greenhouse soil, and for symptomatic and asymptomatic plants.
\end{abstract}

Fusarium virguliforme O'Donnell \& T. Aoki is a soilborne fungus that infects soybean roots and causes root rot, crown rot, and vascular discoloration (20). When the fungus colonizes xylem tissues in roots, the toxins it produces are translocated to leaves, where they cause interveinal chlorosis, necrosis (or leaf scorch), premature defoliation, and flower and pod abortion $(21,26)$. Collectively, these symptoms are referred to as sudden death syndrome (SDS) of soybean. This economically important disease is widely distributed throughout the soybean-producing regions of the United States (26), with estimated yield losses ranging from 11 to 75 million bushels per year between 1997 and 2007 (37). In recent years, SDS has caused particular concern in the Midwest, where outbreaks have been more severe (21) and several states have reported the disease for the first time $(5,8,17,41)$. SDS also occurs in South America, where it is caused by F. tucumaniae T. Aoki, O'Donnell, Yosh. Homma \& Lattanzi; F. brasiliense T. Aoki \& O'Donnell; and an undescribed Fusarium sp. in addition to $F$. virguliforme, which is the only species known to cause SDS in the United States $(1,25)$.

The mechanisms of long-distance spread of $F$. virguliforme are unclear but dispersal likely involves movement of soil, where the pathogen overwinters in the form of chlamydospores on plant debris and associated with the soybean cyst nematode (Heterodera glycines Ichinohe) $(20,26)$. Chlamydospores, together with conidia and mycelia, may serve as inoculum for infection in subsequent growing seasons. Studies on pathogen distribution and inoculum density in soybean fields have been limited $(28,29,32,35)$ due to the lack of practical methods to specifically detect and quantify $F$. virguliforme in soil. A tool to accurately and specifically quantify $F$. virguliforme in soil is needed to clarify the role of inoculum density in disease progress, facilitate SDS risk assessments in soybean fields, and provide insights about mechanisms of pathogen spread.

Corresponding author: L. L. Leandro, E-mail: 1leandro@iastate.edu

Accepted for publication 16 June 2011.

doi:10.1094/PDIS-02-11-0120

(C) 2011 The American Phytopathological Society
SDS management is challenging and requires the use of multiple approaches, with the selection of resistant varieties being of primary importance (26). However, soybean varieties characterized as resistant to $F$. virguliforme exhibit partial resistance because resistance is multigenic $(16,30)$, and resistance in some varieties can be overcome by high inoculum concentrations $(2,14)$. Furthermore, screening for resistance to SDS in greenhouse assays does not consistently predict mature-plant responses in field conditions $(26,34)$, possibly due, in part, to differences in inoculum levels in greenhouse versus field studies. Because SDS development in field conditions is highly dependent on environmental factors $(26,31)$, accurate quantification of $F$. virguliforme in soil could help to improve reliability of resistance screening assays.

Soil dilution plating methods have been used to quantify $F$. virguliforme propagules in soil $(28,29,32)$ but these methods are time consuming, laborious, and often underestimate pathogen density. Isolation is further compounded by fast-growing fungi that can overrun culture plates containing the very slow-growing $F$. virguliforme (26). Dilution-plate methods are also unsuitable for processing numerous samples that would be needed to assess SDS risk based on inoculum densities in soybean fields. In contrast, realtime polymerase chain reaction (PCR) can be used to quantify density of fungal propagules in soil $(7,11,36)$ and may be applicable for studies of soilborne inoculum levels of $F$. virguliforme.

One of the challenges with quantification of $F$. virguliforme in field soil is the presence of closely related Fusarium spp. that are ubiquitous in soil (22). Published real-time PCR assays $(12,18)$ for $F$. virguliforme were based on the mitochondrial small subunit (mtSSU) rDNA region. However, primers developed from this region also amplify DNA from other SDS-causing Fusarium spp., as well as DNA from some $F$. solani (Mart.) Sacc. strains that do not cause SDS but have been isolated from soybean and corn roots in Iowa (unpublished data). The published primers were developed prior to recent findings that the mtSSU locus is highly conserved and unable to resolve species boundaries within the SDS-bean root rot (BRR) clade of the $F$. solani species complex $(1,25)$, which groups the four SDS-causing species with a bean root rot $F$. phaseoli species.

Genetic loci that delimit species boundaries within the SDSBRR clade would be useful for the design of species-specific prim- 
ers and probes. FvToxl is a single-copy gene that has been recently shown to play a major role in causing the leaf scorch component of SDS caused by $F$. virguliforme (6). Because the ability to cause SDS leaf scorch is unique to the SDS-causing species, we hypothesized that the FvToxl gene would be useful for the development of a species-specific assay for $F$. virguliforme. The objective of this study was to develop a real-time PCR assay that distinguishes $F$. virguliforme from the other species within the SDS-BRR clade based on the FvToxl gene.

\section{Materials and Methods}

Fungal isolates and growth conditions. Modified Nash and Snyder medium (MNSM) (28) was used to isolate $F$. virguliforme from roots of diseased soybean plants collected in 2006 and 2007 from Iowa fields. Isolates were subcultured onto potato dextrose agar (PDA; Becton and Dickinson Co., Sparks, MD), and identified based on morphological characteristics (1). Single-spore isolates were obtained and species identification was confirmed using sequence analysis (1). Isolates were stored in sterilized soil (4) in $10-\mathrm{ml}$ glass tubes at $4^{\circ} \mathrm{C}$ until further use. Isolates of the other three SDS-causing species (F. tucumaniae, F. brasiliense, and $F$. cuneirostrum) were obtained from the Agriculture Research Service Culture Collection (NRRL, National Center for Agricultural Utilization Research, Peoria, IL), and single-spore isolates of $F$. solani from corn and soybean were obtained from Dr. Gary Munkvold (Department of Plant Pathology and Microbiology, Iowa State University). Also included in this study were isolates of other species of fungi from the Iowa State University Mycology Teaching Laboratory Collection. Fungal cultures for all isolates (Table 1) were first grown on PDA for 4 days at $25 \pm 2^{\circ} \mathrm{C}$ and then used to inoculate malt yeast extract broth (23). Mycelia were harvested by vacuum infiltration, freeze-dried overnight, and stored at $4^{\circ} \mathrm{C}$ for subsequent DNA isolation.

Design of primers and probe. The sequence of the FvToxl gene was obtained by PCR amplification using primer pair 1983 (5'-CAC CGG ATC CAC GAT GGC GAA GTC CAC ATT CAC

Table 1. Specificity of the TaqMan assay designed from the single-copy FvTox 1 gene compared to two published assays designed from the mitochondrial small subunit (mtSSU) gene sequences

\begin{tabular}{|c|c|c|c|c|c|}
\hline \multirow[b]{2}{*}{ Isolate } & \multirow[b]{2}{*}{ Species } & \multirow[b]{2}{*}{ Host $^{\text {b }}$} & \multicolumn{3}{|c|}{ Detection assays $^{\text {a }}$} \\
\hline & & & FvTox1 & $\mathrm{mtSSU}_{1}$ & $\mathrm{mtSSU}_{2}$ \\
\hline LL0028 & Fusarium virguliforme & Glycine $\max$ & + & + & + \\
\hline LL0009 & F. virguliforme & G. $\max$ & + & + & + \\
\hline NRRL31950 & F. tucumaniae & G. $\max$ & - & + & + \\
\hline NRRL31157 & F. cuneirostrum & G. $\max$ & - & + & + \\
\hline NRRL34938 & F. brasiliense & G. $\max$ & - & + & + \\
\hline $42-\mathrm{T} 8$ & F. solanic & G. $\max$ & - & + & + \\
\hline 295-Т9 & F. solani & G. $\max$ & - & + & + \\
\hline 209-T4 & F. solani & G. $\max$ & - & + & + \\
\hline 9T3 & F. solani & G. $\max$ & - & + & + \\
\hline 5L5 & F. solani & G. $\max$ & - & + & + \\
\hline 42-T8A & F. solani & G. $\max$ & - & + & + \\
\hline 76-L2 & F. solani & G. $\max$ & - & - & - \\
\hline 9T3 & F. solani & G. $\max$ & - & + & + \\
\hline 253-L4 & F. solani & G. $\max$ & - & + & + \\
\hline 295-T6 & F. solani & G. $\max$ & - & + & + \\
\hline 42-L10 & F. solani & G. $\max$ & - & + & + \\
\hline 76-L6 & F. solani & G. $\max$ & - & + & + \\
\hline 458-L10 & F. solani & G. $\max$ & - & + & + \\
\hline 228-T2 & F. solani & G. $\max$ & - & + & + \\
\hline 391-L4 & F. solani & G. $\max$ & - & + & + \\
\hline $35-\mathrm{T} 7$ & F. solani & G. $\max$ & - & + & + \\
\hline 98-L3 & F. solani & G. $\max$ & - & + & + \\
\hline 76-T10 & F. solani & G. $\max$ & - & + & + \\
\hline 11-T3 & F. solani & G. $\max$ & - & + & + \\
\hline 42-T1 & F. solani & G. $\max$ & - & - & - \\
\hline 209-L6 & F. solani & G. $\max$ & - & + & + \\
\hline 295-L5 & F. solani & G. $\max$ & - & + & + \\
\hline FSP185 & F. solani & G. $\max$ & - & - & - \\
\hline $95-164$ & F. solani & Zea mays & - & + & + \\
\hline FSP325PS & F. solani & Z. mays & - & - & - \\
\hline FS94-1A & F. solani & Z. mays & - & - & - \\
\hline F-1 & F. oxysporum & Lactuca sativa & - & - & - \\
\hline F-2 & F. culmorum & L. sativa & - & - & - \\
\hline F-5 & F. culmorum & L. sativa & - & - & - \\
\hline F-9 & $F$. concolor & L. sativa & - & - & - \\
\hline SR-8 & F. subglutinans & L. sativa & - & - & - \\
\hline 17-JC & F. oxysporum & L. sativa & - & - & - \\
\hline CY-6 & F. graminearum & L. sativa & - & - & - \\
\hline CY-10 & F. acuminatum & L. sativa & - & - & - \\
\hline 1022 & F. proliferatum & L. sativa & - & - & - \\
\hline 2192-001 & Alternaria alternata & Daucus carota & - & - & - \\
\hline 269 & A. longissima & D. carota & - & - & - \\
\hline $70-15$ & Magnaporthe grisea & Oryza sativa & - & - & - \\
\hline ATCC 22959 & Rhizopus oligosporus & ND & - & - & - \\
\hline ATCC 11539 & Gloeophyllum trabeum & ND & - & - & - \\
\hline ATCC 24859 & Saccharomyces cerevisiae & ND & - & - & - \\
\hline ATCC 24725 & Phanerochaete chrysosporium & ND & - & - & - \\
\hline ATCC 1003 & Aspergillus oryzae & ND & - & - & - \\
\hline
\end{tabular}

a Symbols: - not detected, + detected, and ND = host not known.

${ }^{\mathrm{b}}$ Host plant from which fungus was isolated.

${ }^{c} F$. solani isolates that did not amplify with mtSSU-based assays were not included. 
CCT TG-3') and 1986 (5'-CCG CGA ATT CTT ACT GTG GGT TGC GCA CAC AGT TG-3') (M. K. Bhattacharyya, unpublished). These primers amplified a 657-bp fragment from representative isolates of the four Fusarium spp. that cause SDS, and the amplicons were sequenced. The sequences were aligned and parts of the nucleotide sequence that showed distinction among species were used to design the forward primer (FV-F, 5'-GCA GGC CAT GTT GGT TCT GTA-3'), reverse primer (FV-R, 5'-GCA CGT AAA GTG AGT CGT CTC ATC-3'), and probe (FV-MGB probe 5'-6FAM ACT CAG CGC CCA GGA MGB N FQ-3') specific to $F$. virguliforme (Fig. 1). Primers and probe were designed with Primer Express software and synthesized by Applied Biosystems (Foster City, CA).

DNA extraction from mycelia. DNA was isolated from lyophilized mycelia following the method of DeScenzo and Harrington (10) and concentrations were determined by absorbance at 260 or $280 \mathrm{~nm}$ with the Nanodrop system (Thermo Fisher Scientific, Wilmington, DE). Ten-fold serial dilutions of $F$. virguliforme genomic DNA were prepared in triplicate and used in real-time PCR reactions.

DNA extraction from $\boldsymbol{F}$. virguliforme conidia. To determine whether conidia could be used for quantification of fungal inoculum density, 4-day-old plates of $F$. virguliforme (LL0028) were flooded with Tris EDTA (TE) buffer, and conidial concentrations were determined using a hemocytometer. Ten-fold serial dilutions $\left(10^{8}\right.$ to $10^{0}$ conidia $\left./ \mathrm{ml}\right)$ of the conidia were prepared in $20 \%$ nutrient broth (40). For each conidial concentration, $1 \mathrm{ml}$ of sample was transferred to 2-ml microcentrifuge tubes containing $1 \mathrm{ml}$ of 0.5 mm-diameter silica beads (Biospec Products, Inc., Bartlesville, $\mathrm{OK}$ ), and the conidia were homogenized at a speed of 6 for $40 \mathrm{~s}$ in a homogenizer (FastPrep-24; MP Biomedicals, Solon, OH). Three microcentrifuge tubes were prepared per dilution. The tubes were heated on a hot plate for $5 \mathrm{~min}$ at $100^{\circ} \mathrm{C}$, cooled on ice for $5 \mathrm{~min}$, and centrifuged for 1 min until the conidial debris formed a pellet. Supernatant containing the DNA $(5 \mu \mathrm{l})$ was used directly for realtime quantitative PCR.

DNA extraction from soil infested with $F$. virguliforme. Soil samples were artificially infested with conidia to evaluate the ability to extract and subsequently amplify $F$. virguliforme DNA from soil. The effect of soil substrate and non-target soil microflora on efficiency of detection using PCR amplification was determined by comparing the yield of fungal genomic DNA amplified from sterilized and nonsterilized soil substrate spiked with conidia. Soil was collected from a soybean field with no history of SDS from Curtiss Farm of Iowa State University, Ames. The absence of $F$. virguliforme propagules in the soil was confirmed by extracting total soil DNA from three 250-mg subsamples and running PCR reactions with designed primers. One part of the soil sample was autoclaved for $60 \mathrm{~min}$ at $121^{\circ} \mathrm{C}$ for two consecutive days (sterilized soil sample), and the nonautoclaved part constituted the nonsterilized soil. $F$. virguliforme conidial suspensions $\left(2 \mathrm{ml}\right.$ each of $10^{7}, 10^{6}, 10^{5}$, $10^{4}, 10^{3}, 10^{7}, 10$, and 1 conidia/ml) were added to $2 \mathrm{~g}$ of the sterilized and nonsterilized soil in 15-ml conical tubes and mixed. Three 250-mg samples of each of these mixtures were weighed and freeze dried. Controls consisted of 250-mg soil samples mixed with $2 \mathrm{ml}$ of distilled water (11). Total soil DNA was isolated from each soil sample using the MoBio UltraClean Soil DNA isolation kit (MoBio Laboratories, Solana Beach, CA) with the following modifications. After adding $60 \mu \mathrm{l}$ of solution 1 from the MoBio kit, the soil-buffer mixture was homogenized at a speed level of 6 for 4 $s$ in the Fast Prep homogenizer. The subsequent DNA extraction steps were performed as described in the instruction manual.

Sensitivity and specificity of the PCR assay. PCR reactions were carried out in a total reaction volume of $25 \mu$, containing $5 \mu \mathrm{l}$ of DNA template, $0.3 \mu \mathrm{l}$ of each primer ( $25 \mu \mathrm{M}$ each), and $0.5 \mu \mathrm{l}$ of the TaqMan probe $(10 \mu \mathrm{M})$ in $12.5 \mu \mathrm{l}$ of PerfeCTa qPCR SuperMix

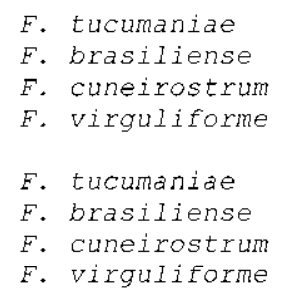

F. Eucunariae

F. brasiliense

F. cuneirostrum

F. virguliforme

F. Eucumaniae

F. brasiliense

F. cuneirostrum

F. virguliforme

E. Eucumaniae

F. brasiliense

$F$. cuneirostrum

F. virguiforme

F. Eucumaniae

F. brasiliense

F. Virguifforme
F. Cuneirostrum

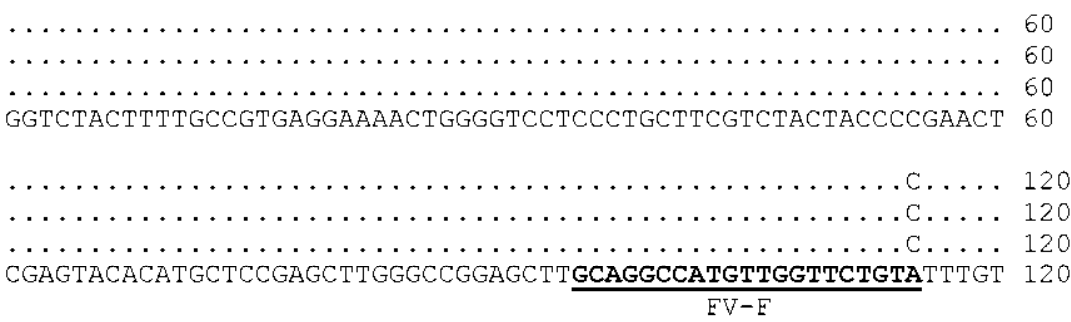

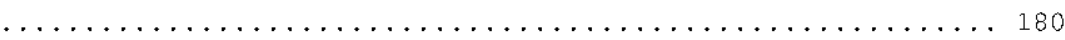

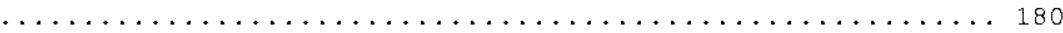

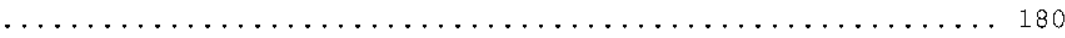

CGAGGCTGGTGCCATCTGCCGGATGGCARCgtacgtgaccctctcatacatgtcgatac 180

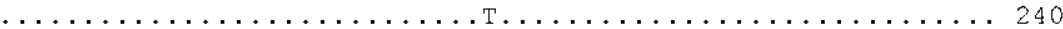

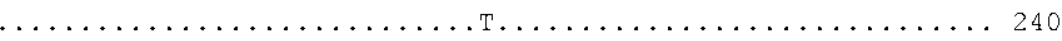

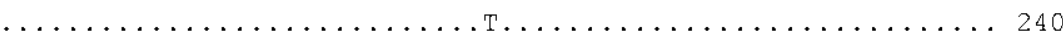

cgattactgacaadetgcagACTCAGCGCCCAGGACCGATGCGCCCCGATCGAGTTCTTT 240

FV-MGB probe

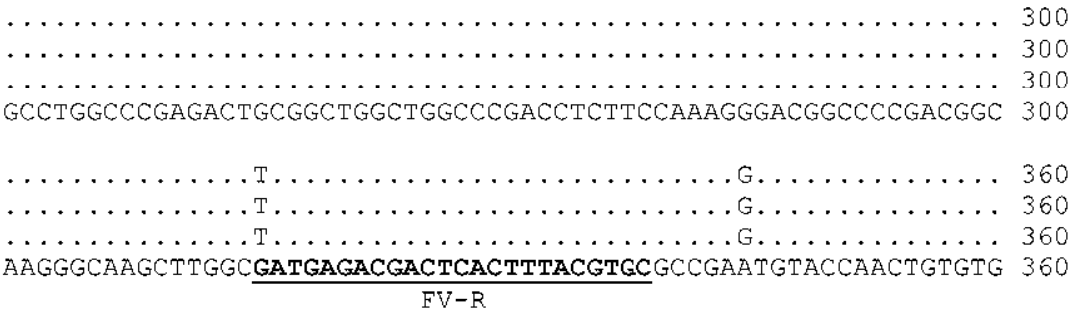

$\mathrm{FV}-\mathrm{R}$

F. Eucumaniae

F. brasiliense

F. cuneirostrum

F. virguliforme

Fig. 1. Multiple sequence alignment of part of the FvTox1 gene sequence and polymorphic sites used to design Fusarium virguliforme-specific primers and TaqMan MGB probe. Lowercase nucleotides represent the second intron of the gene. Dots represent matching nucleotides to the $F$. virguliforme FvTox1 gene sequence. 
with Rox (Quanta BioSciences, Inc., Gaithersburg, MD). The thermal profile was $10 \mathrm{~min}$ at $95^{\circ} \mathrm{C}$ followed by 40 cycles of $15 \mathrm{~s}$ at $95^{\circ} \mathrm{C}$ and $45 \mathrm{~s}$ at $60^{\circ} \mathrm{C}$ (Bio-Rad IQ5 thermal cycler; Bio-Rad Laboratories, Hercules, CA). The threshold value of the real-time PCR machine was set manually at 100 , and any signal $<100$ was considered background fluorescence.

To determine specificity, the primer pairs were tested on total genomic DNA (50 ng) from 49 fungal isolates representing Fusarium spp. diversity and species commonly found in association with soybean roots (Table 1). The same samples were tested using the previously published real-time PCR assays $(12,18)$. To determine the sensitivity of the assay, the ability of the primers to amplify the target fragment from decreasing concentrations of $F$. virguliforme using the DNA obtained from 10-fold serial dilutions of $F$. virguliforme total genomic DNA, conidial suspensions, and spiked soil was tested. The quantification cycle $\left(\mathrm{C}_{\mathrm{q}}\right.$; fractional PCR cycle at which the target is quantified in a given sample) values obtained for each dilution series were used to generate standard curves for absolute quantification of the target DNA in soil and root samples.

Assay validation. To assess reliability of the assay in detecting and quantifying $F$. virguliforme in native soil, total DNA was extracted from four soil samples obtained from infested potted soil used in greenhouse pathogenicity tests and eight samples obtained from soybean fields in Iowa with a history of SDS. DNA was extracted in triplicate from each soil sample as previously described and the FvToxl gene was amplified using the TaqMan assay. DNA was also extracted from roots of diseased soybean plants collected from a soybean field infested with SDS and the target gene was quantified using the TaqMan assay. Because quantification cycle values vary between experiments, DNA obtained from 10-fold serial dilutions of the conidia in nonsterilized soil was included in each run of the test soil samples for calibration purposes. For all runs, the $18 \mathrm{~S}$ rDNA primers and probe were included as the endogenous amplification control (IAC) (33). Foliar and root disease severity were assessed on the greenhouse plants in pots from which soil samples were collected. SDS foliar disease severity, defined as the percentage of leaf area showing chlorosis or necrosis typical of SDS, was rated at 10,14, 18, 22, 26, and 30 days after inoculation. Root rot severity was rated 30 days after inoculation as the percentage of root area showing brown discoloration.

Data analysis. A linear-regression equation was obtained from each standard curve. The concentrations of target DNA in test root and soil samples were calculated by comparing the $\mathrm{C}_{\mathrm{q}}$ values obtained for these samples with the crossing point values of the linearregression line of the standard curve of both the mycelia and the spiked-soil standards. The amount of the target DNA in soil was expressed as number of conidia of $F$. virguliforme per gram of soil. Amplification efficiency (E) was calculated according to the equation $\mathrm{E}=\left[10^{(-1 / \mathrm{slope})}\right]-1$. Pearson correlation analysis was conducted to determine the association between conidial density in soil, foliar area under disease progress curve (AUDPC), and root rot severity.

\section{Results}

Specificity of $\boldsymbol{F}$. virguliforme primers and probe. The FvTox 1 gene showed sufficient interspecies divergence to produce amplification products specific to $F$. virguliforme. The sequence of the FvToxl gene in $F$. virguliforme differed by four single nucleotide polymorphisms (SNPs) from each of the three SDS-causing species from South America (Fig. 1). The TaqMan probe and primers amplified a 200-bp single amplicon from pure cultures of $F$. virguliforme and not from any of the other fungal isolates tested (Table 1). The FvToxl assay was more specific than the published $F$. virguliforme $\mathrm{mtSSU}$-based assays $(12,18)$ because it detected only $F$. virguliforme (Tables 1 and 2 ).

Sensitivity of the primers and probe. There was a linear relationship $\left(R^{2}=0.999 ; \mathrm{E}=1.0\right)$ between $F$. virguliforme genomic DNA concentration and real-time quantification cycles using the FvToxl primers and probe (Fig. 2). The pathogen was detected at template concentrations of $5 \mathrm{pg} / \mu \mathrm{l}$ (Fig. 2). A similar linear pattern of amplification was obtained from DNA derived from dilution series of conidia $\left(R^{2}=0.979, \mathrm{E}=2.0\right)$. The detection limit of the target amplicon was 1,000 conidia/ml of suspension (Fig. 3A). When conidia were added to both sterilized and nonsterilized soil, a consistent and proportionate amount of DNA was extracted and quantified across the range of inoculum concentrations $\left(R^{2}=\right.$ $0.960 ; \mathrm{E}=1.1$ ) (Fig. 3B). At $10^{3}$ conidia/g soil, $F$. virguliforme was detected in all three replicates whereas, at $10^{2}$ conidia/g of soil, the DNA target was detected in only two of the three replicates (G. C. Y. Mbofung, unpublished data). Thus, the limit of detection was defined as $10^{3}$ conidia/g soil. Dilution series from artificially infested soils resulted in amplicons of the same size as from pure cultures. Quantification cycle values for DNA obtained from both sterilized and nonsterilized soil were similar (for sterilized soil, data not shown). The FvToxl assay detected its target five quantification cycles later than the mtSSU assay (Table 2).

Table 2. Specificity and sensitivity of the TaqMan assay designed from the single-copy FvTox 1 gene compared to a TaqMan assay designed from the mitochondrial small subunit (mtSSU) gene in distinguishing Fusarium virguliforme from other sudden death syndrome (SDS) and non-SDS-causing species

\begin{tabular}{|c|c|c|c|c|c|}
\hline \multirow[b]{3}{*}{ Isolate } & \multirow[b]{3}{*}{ Species } & \multicolumn{4}{|c|}{ Detection $^{\mathrm{a}}$} \\
\hline & & \multicolumn{2}{|c|}{ FvTox1 } & \multicolumn{2}{|c|}{$\overline{\mathrm{mtSSU}} \mathrm{U}_{2}$} \\
\hline & & $C_{q}$ value & Detection & $C_{q}$ value & Detection \\
\hline $2 \mathrm{~T} 2$ & Fusarium solani & 34.77 & - & 19.42 & + \\
\hline FS94-1A & F. solani & 33.83 & - & 33.41 & - \\
\hline 209L6 & F. solani & 33.99 & - & 19.23 & + \\
\hline FSP185 & F. solani & 34.61 & - & 33.33 & - \\
\hline FB15II & F. virguliforme & 21.05 & + & 15.55 & + \\
\hline NRRL22292 & F. virguliforme & 21.03 & + & 14.16 & + \\
\hline Mont 1 & F. virguliforme & 20.29 & + & 14.33 & + \\
\hline LL0009 & F. virguliforme & 21.89 & + & 15.99 & + \\
\hline NRRL31950 & F. tucumaniae & 33.94 & - & 14.24 & + \\
\hline NRRL31793 & F. tucumaniae & 34.99 & - & 13.11 & + \\
\hline NRRL31085 & F. tucumaniae & 33.79 & - & 14.62 & + \\
\hline NRRL34938 & F. brasiliense & 35.27 & - & 15.22 & + \\
\hline NRRL22743 & F. brasiliense & NA & - & 14.67 & + \\
\hline NRRL22678 & F. brasiliense & 34.94 & - & 15.08 & + \\
\hline NRRL31104 & F. cuneirostrum & 34.02 & - & 15.13 & + \\
\hline NRRL31157 & F. cuneirostrum & 33.45 & - & 14.88 & + \\
\hline NRRL22275 & F. cuneirostrum & NA & - & 14.48 & + \\
\hline NRRL22158 & F. cuneirostrum & 34.74 & - & 19.21 & + \\
\hline Control & Water & 33.34 & - & 33.36 & - \\
\hline
\end{tabular}

a Symbols: - not detected and + detected. Quantification cycle $\left(\mathrm{C}_{\mathrm{q}}\right)$ values $\geq$ the value obtained for a water control were considered not detected; NA = no amplification. 
Validation of the real-time PCR assay. From the 12 samples used to test the applicability of the assay for detection in soil, the detectable number of conidia per gram of soil ranged from 0 to $10^{6}$, with infested greenhouse samples having the highest conidial densities (Fig. 4). Soil PCR products exhibited $100 \%$ sequence homology to the pure culture (G. C. Y. Mbofung, unpublished). In soil from the greenhouse experiment, inoculum density of $F$. virguliforme was positively correlated $(r=0.853, P=0.004)$ with foliar AUDPC but not correlated $(P=0.266)$ with root rot severity. The amount of target DNA estimated in the roots of symptomatic plants ranged between 2.5 and $3.4 \mathrm{ng} / \mathrm{mg}$ of fresh root tissue.

\section{Discussion}

The real-time PCR assay reported here is the first to directly quantify $F$. virguliforme in soil substrate. The assay was highly specific to $F$. virguliforme and enabled the quantification of genomic DNA of $F$. virguliforme in both artificially and naturally infested field soils. The assay developed was sensitive enough to detect genomic DNA at $25 \mathrm{pg} / \mathrm{g}$ of soil and $F$. virguliforme at 1,000 conidia/g of soil. Because the pathogen persists in soil after cultivation of soybean, the capability to quantify $F$. virguliforme in soil will facilitate epidemiological studies on the relationship between inoculum density and disease development, and permit identification of high-risk fields that can either be avoided or else managed to reduce yield losses due to SDS (32).

The primers and probe used in the assay were developed based on the FvToxl gene of $F$. virguliforme (6). This gene codes for a proteinaceous phytotoxin involved in the development of SDS leaf scorch. Two other phytotoxins, monorden (3) and a $17-\mathrm{kDa}$ proteinaceous toxin (15), have been isolated from cell-free culture filtrates of $F$. virguliforme and shown to cause necrosis on soybean leaves. Because $F$. virguliforme has never been isolated from aboveground plant parts (27), the toxins are thought to be produced by the fungus in colonized roots and translocated to the leaves via the xylem (21).

Comparison of the four SDS-causing species showed that the sequences of the FvToxl gene contained four SNPs unique to $F$. virguliforme, three of which were used to develop the specific primers and probe. Because the FvToxl gene sequences were identical for F. tucumaniae, F. brasiliense, and F. cuneirostrum, this gene cannot be used to distinguish among the causal agents of SDS in South America (25). Preliminary work to amplify the FvToxl gene in $F$. solani isolates (unpublished data) showed very low similarity of the gene with the SDS-causing species, consistent with the inability of $F$. solani to cause SDS foliar symptoms.

The designed primers and probe amplified a single fragment only from $F$. virguliforme but not from pure isolates of other fungal

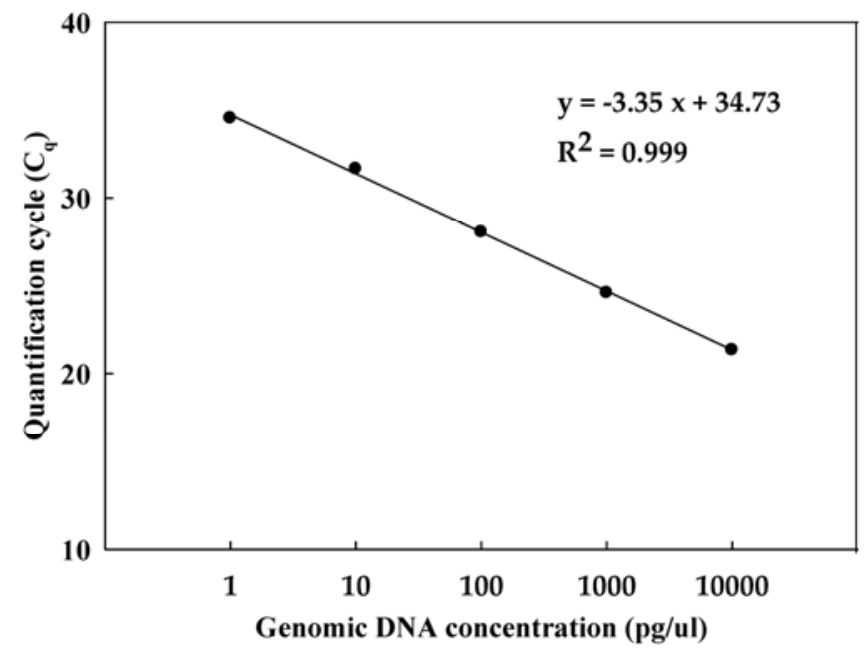

Fig. 2. Standard curve for absolute quantification of genomic DNA generated with 10 -fold serial dilutions of genomic DNA isolated from pure cultures of Fusarium virguliforme. The detection limit for genomic DNA was $25 \mathrm{pg}$. species or other Fusarium spp. from nonsterilized soil, confirming their reliability for specifically detecting $F$. virguliforme and indicating no undesired cross-reactivity with non-target genomic DNA. Furthermore, the FvToxl gene region was shown to be more specific for $F$. virguliforme than previously used regions because no amplification occurred with the $F$. solani strains that cross-reacted with published assays based on the mtSSU region $(12,18)$. This region was recently reported as unsuitable for distinguishing species within the SDS-BRR clade of the F. solani complex (25). The fact that most of the $F$. solani isolates tested in this study amplified with the published mtSSU real-time PCR assays while other $F$. solani isolates did not may be a consequence of the genetic variation found within the $F$. solani species complex (24). The specificity of the assay developed in this study will allow detection of $F$. virguliforme in field soil where other Fusarium spp., including $F$. solani, are present.

The similar quantification cycle values obtained for DNA extracted from both sterilized and nonsterilized soil indicated a high efficiency in DNA extraction and effectiveness of the assay to detect the target despite the presence of other soil organisms. Because the target fragment was detected consistently from dilutions of genomic DNA of $5 \mathrm{pg} / \mu \mathrm{l}$, the limit of detection was defined as DNA at $5 \mathrm{pg} / \mu \mathrm{l}$. The sensitivity of the assay was set to $1,000 \mathrm{co}-$ nidia/g of nonsterilized soil due to consistent amplification at this inoculum density but the assay was sensitive enough to often detect 100 conidia/g of soil. Similar soil densities $\left(10^{2}\right.$ to $10^{3} \mathrm{CFU} / \mathrm{g}$ of
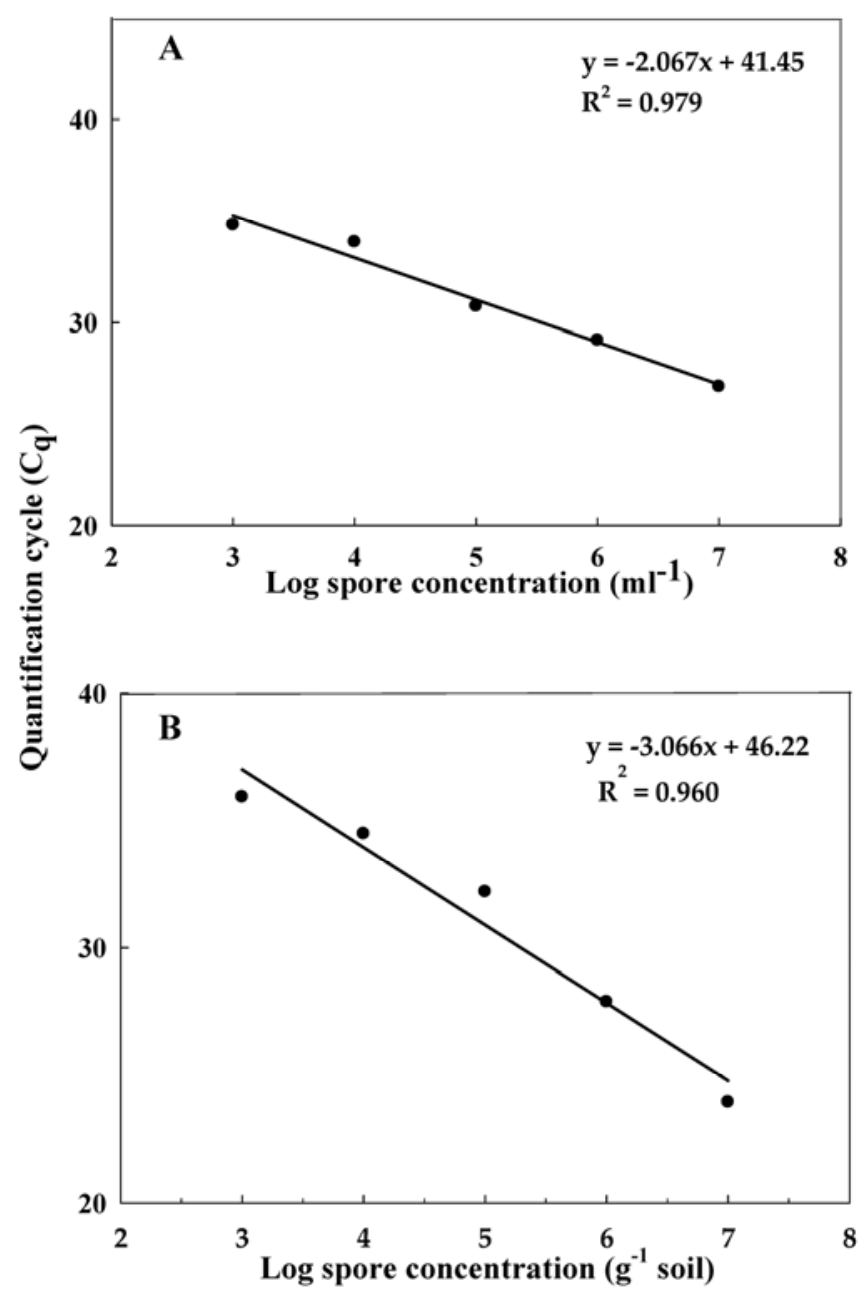

Fig. 3. A, Standard curve for absolute quantification of DNA from conidial suspensions. Detection limit for conidial suspension was 1,000 conidia/ml. B, Standard curve for absolute quantification of DNA from soil artificially infested with conidia. Detection limit for conidia in soil was 1,000 conidia/g of soil. All curves show a linear relationship between quantification cycle values and initial DNA concentrations. 
soil) of SDS pathogen have been reported in symptomatic soybean fields based on soil dilution plating methods $(28,29,32)$, suggesting that the PCR assay is adequate for detecting $F$. virguliforme at densities capable of causing disease. However, a major limitation with using PCR to detect targets from complex environmental samples, such as soil, is the presence of PCR inhibitors in the extracted DNA (12). This limitation was indicated by the lower $R^{2}$ values of the standard curves obtained for soil artificially infested with conidia compared with pure conidial suspensions. Although total soil DNA obtained using commercially available kits was of high quality and suitable for the assay, it is possible that continued optimization of DNA extraction and purification protocols could further improve the assay sensitivity.

Although F. virguliforme propagules in soil include mycelia, conidia, conidiophores, and chlamydospores (26), conidia were used as a calibrator for generating standard curves and as the unit for expression of inoculum density in this study. Conidia have been consistently used as a calibrator for quantification of inoculum densities of plant pathogens from soil because of ease of calculation $(7,9,11,19,38)$, whereas calibration using mycelia or chlamydospores is possible but complicated. Nevertheless, it is theoretically possible to quantify target DNA from any source if standard curves based on known concentrations of genomic DNA are used. The assay could, for example, be used to quantify the pathogen in infected soybean plants, as shown by the amplification of the FvToxl gene from roots of symptomatic field plants.

The availability of species-specific primers to quantify $F$. virguliforme in soil will contribute significantly to epidemiological studies on SDS. A better understanding of the relationship between inoculum density in soil and disease development $(12,13,32)$ would facilitate predictions of disease risk in individual fields and improve reliability of screening assays for disease resistance (22). The strong correlations obtained in this study between inoculum density and foliar severity shows that the real-time PCR assay will be useful for studying these relationships. Quantification of pathogen density in soil may also provide essential insights about the effectiveness of cultural practices for SDS management. Recent findings that $F$. virguliforme survives on corn residue (39), for example, stress the importance of monitoring pathogen dynamics in soil under different cropping systems (29). Studies on F. virguliforme distribution in soybean production areas and its interactions with SCN (20) may also clarify the mechanisms of pathogen spread. Finally, quantification of $F$. virguliforme in roots could be useful for evaluating SDS resistance in soybean varieties and for early diagnosis of the pathogen in asymptomatic plants.

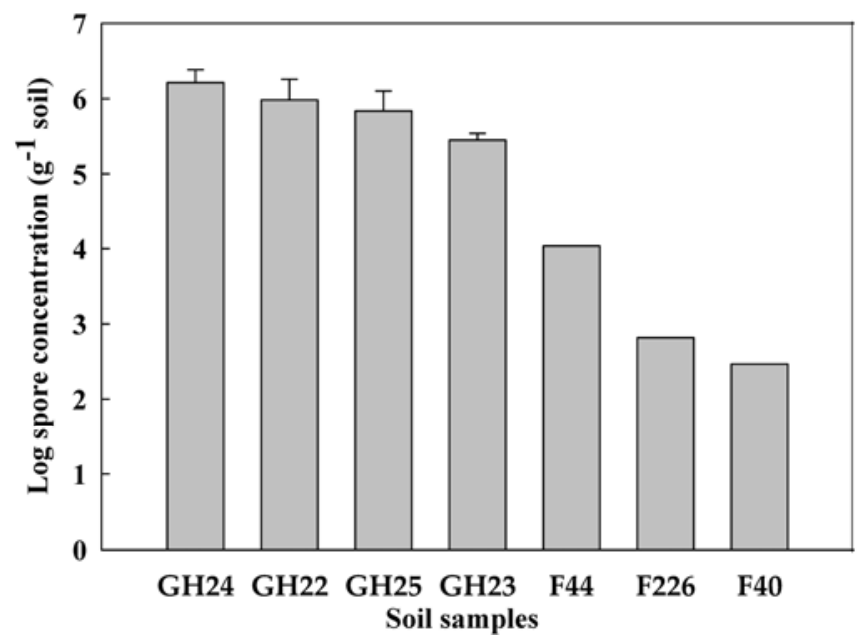

Fig. 4. Fusarium virguliforme conidial density in 7 of the 12 soil samples tested, 4 from greenhouse studies (GH22, GH23, GH24, and GH25) and 3 from soybean fields (F44, F226, and F40). Conidial densities detected in each soil sample are the means of three replications and were calculated using the regression equation $y=$ $-3.066 x+46.22$. Error bars represent standard error of the mean.

\section{Acknowledgments}

This work was funded by the Iowa Soybean Association. We thank G. Munkvold for providing isolates of Fusarium solani species isolated from corn and soybean and K. O'Donnell for providing isolates of F. tucumaniae, F. brasiliense, and F. cuneirostrum.

\section{Literature Cited}

1. Aoki, T., O'Donnell, K., and Lattanzi, M. M. 2005. Sudden death syndrome of soybean in South America is caused by four species of Fusarium: Fusarium brasiliens sp. nov., F. cuneirostrum sp. nov., F. tucumaniae, and $F$. virguliforme. Mycoscience 46:162-183.

2. Arruda, G. M. T., Miller, R. N. G., Ferreira, M. A. S. V., and Café-Filho, A. C. 2005. Morphological and molecular characterization of the sudden death syndrome pathogen of soybean in Brazil. Plant Pathol. 54:53-65.

3. Baker, R. A., and Nemec, S. 1994. Soybean sudden death syndrome: isolation and identification of a new phytotoxin from cultures of the causal agent, Fusarium solani. (Abstr.). Phytopathology 84:1144.

4. Bakerspigel, A. 1953. Soil as a storage medium for fungi. Mycologia 45:596-604.

5. Bernstein, E. R., Atallah, Z. K., Koval, N. C., Hudelson, B. D., and C. R. Grau. 2007. First report of sudden death syndrome of soybean in Wisconsin. Plant Dis. 91:1201.

6. Brar, H. K., Swaminathan, S., and Bhattacharyya, M. K. 2011. The Fusarium virguliforme toxin FvTox1 causes foliar sudden death syndrome-like symptoms in soybean. Mol. Plant-Microbe Interact. Online publication. doi:10.1094/MPMI-12-10-0285.

7. Brierley, J. L., Stewart, J. A., and Lees, A. K. 2009. Quantifying potato pathogen DNA in soil. Appl. Soil Ecol. 41:234-238.

8. Chilvers, M. I, and Brown-Rytlewski, D. E. 2010. First report and confirmed distribution of soybean sudden death syndrome caused by Fusarium virguliforme in Southern Michigan. Plant Dis. 94:164.

9. Cullen, D. W., Lees, A. K., Toth, I. K., and Duncan, J. M. 2002. Detection of Colletotrichum coccoides from soil and potato tubers by conventional and quantitative real-time PCR. Plant Pathol. 51:281-292.

10. DeScenzo, R. A., and Harrington, T. C., 1994. Use of $(\text { CAT })_{5}$ as a DNA fingerprint probe for fungi. Phytopathology 84:534-539.

11. Fillion, M., St-Arnaud, M., and Jabaji-Hare, S. H. 2003. Direct quantification of fungal DNA from soil substrate using real-time PCR. J. Microbiol. Methods 53:67-76.

12. Gao, X., Jackson, T. A., Lambert, K. N., Li, S., Hartman, G. L., and Niblack, T. L. 2004. Detection and quantification of Fusarium solani f. sp. glycines in soybean roots with real-time quantitative polymerase chain reaction. Phytopathology 88:1372-1380.

13. Gray, L. E., and Achenbach, L. A. 1996. Severity of foliar symptoms and root and crown rot of soybean inoculated with various isolates and inoculum rates of Fusarium solani. Plant Dis. 80:1197-1199.

14. Hartman, G. L., Huang, Y. H., Nelson, R. L., and Noel, G. R. 1997. Germplasm evaluation of Glycine max for resistance to Fusarium solani, the causal organism of sudden death syndrome. Plant Dis. 81:515-518.

15. Jin, H., Hartman, G. L., Nickel, C. D., and Widholm, J. M. 1996. Characterization and purification of a phytotoxin produced by Fusarium solani, the causal agent of soybean sudden death syndrome. Phytopathology $86: 277-282$.

16. Kazi, S., Shultz, J., Afzal, J., Johnson, J., Njiti, V. N., and Lightfoot, D. A. 2008. Separate loci underlie resistance to root infection and leaf scorch during soybean sudden death syndrome. Theor. Appl. Genet. 116:967-977.

17. Kurle, J. E., Gould, S. L., Lewandowski, S. M., Li, S., and Yang, X. B. 2003. First report of sudden death syndrome (Fusarium solani f. sp. glycines) of soybean in Minnesota. Plant Dis. 87:449.

18. Li, S., Hartman, G. L., Domier, L. L., and Boykin, D. 2008. Quantification of Fusarium solani f. sp. glycines isolates in soybean roots by colony-forming unit assays and real-time quantitative PCR. Theor. Appl. Genet. 117:343-352.

19. Luo, Y., Gao, W., Doster, M., and Michailides, T. J. 2009. Quantification of conidial density of Aspergillus flavus and A. parasiticus in soil from almond orchards using real-time PCR. J. Appl. Microbiol. 106:1649-1660.

20. Melgar, J., Roy, K. W., and Abney, T. S. 1994. Sudden death syndrome of soybean: etiology, symptomatology, and effects of irrigation and Heterodera glycines on incidence and severity under field conditions. Can. J. Bot. 72:1647-1653.

21. Navi, S. S., and Yang, X. B. 2008. Foliar symptom expression in association with early infection and xylem colonization by Fusarium virguliforme (formerly $F$. solani $\mathrm{f}$. sp. glycines), the causal agent of soybean sudden death syndrome. Plant Health Progress. Online publication. doi:10.1094/PHP2008-0222-01-RS.

22. Njiti, V. N., Johnson, J. E., Torto, T. A., Gray, L. E., and Lightfoot, D. A. 2001. Inoculum rate influences selection for field resistance to soybean sudden death syndrome in the greenhouse. Crop Sci. 41:1726-1731.

23. O'Donnell, K. 1992. Ribosomal DNA internal transcribed spacers are highly divergent in the phytopathogenic ascomycete Fusarium sambucinum (Gibberella pulicaris). Curr. Genet. 22:213-220.

24. O'Donnell, K. 2000. Molecular phylogeny of the Nectria haematococcaFusarium solani species complex. Mycologia 92:919-938. 
25. O'Donnell, K., Sink, S., Scandiani, M. M., Luque, A., Colletto, A., Biasoli, M., Lenzi, L., Salas, G., González, V., Ploper, D. L., Formento, N., Pioli, R. N., Aoki, T., Yang, X. B., and Sarver, B. A. J. 2010. Soybean sudden death syndrome species diversity within North and South America revealed by multilocus genotyping. Phytopathology100:58-71.

26. Roy, K. W., Hershman, D. E., Rupe, J. C., and Abney, T. S. 1997. Sudden death syndrome of soybean. Plant Dis. 81:1100-1111.

27. Roy, K. W., Lawrence, G. W., Hodges, H. H., McLean, K. S., and Killebrew, J. F. 1989. Sudden death syndrome of soybean: Fusarium solani as incitant and relation of Heterodera glycines to disease severity. Phytopathology 79:191-197.

28. Rupe, J. C., Robbins, R. T., Becton, C. M., Sabbe, W. A, and Gbur, E. E. Jr. 1999. Vertical and temporal distribution of Fusarium solani and Heterodera glycines in fields with sudden death syndrome of soybean. Soil Biol. Biochem. 31:245-251.

29. Rupe, J. C., Robbins, R. T., and Gbur, E. E., Jr. 1997. Effect of crop rotation on soil population densities of Fusarium solani and Heterodera glycines and on the development of sudden death syndrome of soybean. Crop Prot. 16:575-580.

30. Sanitchon, J., Vanavichit, A., Chanprame, S., Toojinda, T., Triwitayakom, K., Njiti, V. N., and Srinives, P. 2004. Identification of simple sequence repeat markers linked to sudden death syndrome resistance in soybean. Sci. Asia 30:205-209.

31. Scherm, H., and Yang, X. B. 1996. Development of sudden death syndrome of soybean in relation to soil temperature and soil water matric potential. Phytopathology 86:642-649.

32. Scherm, H., Yang, X. B., and Lundeen, P. 1998. Soil variables associated with sudden death syndrome in soybean fields in Iowa. Plant
Dis. 82:1152:1157.

33. Shou, H., Bordallo, P., and Wang, K. 2004. Expression of the Nicotiana protein kinase (NPK1) enhanced drought tolerance in transgenic maize. J. Exp. Bot. 55:1013-1019.

34. Torto, T. A., Njiti, V. N., and Lightfoot, D. A. 1996. Loci underlying resistance to sudden death syndrome and Fusarium solani in field and greenhouse assays do not correspond. Soybean Genet. Newsl. 23:163-166.

35. Vick, C. M., Chong, S. K., Bond, J. P., and J. S. Russin. 2003. Response of soybean sudden death syndrome to subsoil tillage. Plant Dis. 87:629-632.

36. Wang, Y., Zhang, W., Wang, Y., and Zheng, X. 2006. Rapid and sensitive detection of Phytophthora sojae in soil and infected soybeans by speciesspecific polymerase chain reaction. Can. J. Microbiol. 46:633-642.

37. Wrather, J. A., and Koenning, S. R. 2009. Effects of diseases on soybean yields in the United States 1996 to 2007. Plant Health Progress. Online publication. doi:10.1094/PHP-2009-0401-01-RS.

38. Xiang, M. C., Xiang, P. A., Jiang, X. Z., Duan, W. J., and Liu, X. Z. 2010. Detection and quantification of the nematophagous fungus Hir sutella minnesotensis in soil with real-time PCR. Appl. Soil Ecol. 44:170 175.

39. Yang, X. B., and Navi, S. S. 2010. Good harvest in corn should help manage soybean SDS. ICM News 9/10/2010. Online publication. http://www. extension.iastate.edu/CropNews/2010/0910yang.htm

40. Zhou, G., Wong, W. Z., Ong, T, and Chen, B. 2000. Development of fungus-specific PCR assay for detecting low-level fungi in an indoor environment. Mol. Cell. Probes 14:339-348.

41. Ziems, A. D., Giesler, L. J., and Yuen, G. Y. 2006. First report of sudden death syndrome of soybean caused by Fusarium solani f. sp. glycines in Nebraska. Plant Dis. 90:109. 